\title{
The Design and Analysis of Food Safety Chain System Based on the Economic Effects Mechanism
}

\author{
Huang Rong* and Xu Lulu
}

\author{
School of Management, Guangdong University of Technology, Guangzhou, China
}

\begin{abstract}
In recent years, food safety problems have become increasingly serious in China, and major food safety accidents have seriously affected people's daily lives, having negative influence on the healthy development of the food industry and the whole economy. Therefore, it is necessary to analyse existing problems of food safety, further study the main cause of frequent incidents of food safety, and propose the corresponding countermeasures. In the economic analysis, both the production efficiency and environment efficiency have been discussed. According to the changes of farmer-household's production and resident's consumption, factors influencing production and consumption behaviour related to food safety have been analysed empirically, and the economic and policy meaning of the results have been summarized.
\end{abstract}

Keywords: Food safety chain, economy mechanism, environment efficiency, consumption, management.

\section{INTRODUCTION}

Food safety, which is directly related to the sound development of the people's health and the social economy, is one of the world' $s$ hot issues nowadays. In recent years, Chinese food safety incidents have been occurring frequently, most of which have caused very serious consequences and adverse effects. With the rapid development of Chinese economy, profits and efficiency are becoming a major goal of the food enterprise development, which has brought a lot of food safety hazards. Food from the farm to the consumers, usually go through multiple supply chain links such as plant breeding, circulation, processing, consumption, $\mathrm{r}$ recycling, etc. Referring to the statistical data, each links have suffered safe problems in different degrees [1].

The Practical significance of research of the issue of food safety is not limited to the importance and urgency of the problem itself in our country at this stage, but also in the broader sense, a concrete attempt to answer how to effectively protect people's livelihood, improve social management and national soft power. Investigation of the participants who related to food security interests economic behaviour from the economic point of view, will help in the rational analysis of the efficiency of various policy measures, providing a reliable theoretical support for the design of policy formulation and related systems. On the status of research in this area, it's still needs to be studied in a deeper and expand range with respect to economics analysis of food safety issues at the micro foundation level. In particular, focusing on the reality of our situation, starting from the enterprise's economic behaviour, build a clear theoretical framework to analyse microscopic domestic food safety problems, it is full of great theoretical significance.

Especially in the dairy industry we show that the competition pressure is not the crucial reason. If the market is large enough and the capacity of high quality goods under low investment is relatively small, firms are not willing to make enough investment in the quality control and are inclined to set low price for big sales, which would be viewed by consumers as an imperfect signal of high investment. To strengthen the supervising will not change the 'insufficient investment and big sales' status, but will increase the probability of high investment and therefore improve the quality on average [2].

According to the background and relevant researches home and abroad, the paper defined the intension and extension of food safety scientifically, summarized the major factors that affect food safety and its development through the development experiences and scientific and technical standards. In the part of economic analysis, from the behaviours related with the ensuring and promoting of food safety.

\section{LITERATURE REVIEW}

Food can transmit disease from person to person as well as serve as a growth medium for bacteria that can cause food poisoning. In developed countries there are intricate standards for food preparation, whereas in lesser developed countries the main issue is simply the availability of adequate safe water, which is usually a critical item. In theory, food poisoning is $100 \%$ preventable. The five key principles of food hygiene, according to WHOM, are: 
1) Prevent contaminating food with pathogens spreading from people, pets, and pests.

2) Separate raw and cooked foods to prevent contaminating the cooked foods.

3) Cook foods for the appropriate length of time and at the appropriate temperature to kill pathogens.

4) Store food at the proper temperature.

5) Do use safe water and raw materials.

For food safety, including the safety of food production and the safety of food consumption. Foreign research on safe food production time is not long, and domestic research in this area is not much. But with respect to the safety of food production, in terms of domestic and international research on the safety of food consumption is relatively mature. So we mainly pay our attention to aspect of the production of safety food [4]. But Food is not just issues involving the security of supply of processing enterprises, but also involving the production and distribution and marketing of farmers and many other aspects. Based on this, we will open our horizons, mainly regarded the security of the food supply chain as the main line, making a behaviour of economic agents combing research literature on the chain and focus on refining the study of the interaction mechanism between the various actors to demonstrate the safety of the food supply path dependence, which also a logical system of this paper (Fig. 1).

In the part of management study the paper evaluated the system of market access of food safety from supply, demand as well as welfare influence, according to its enforcement in the overall manage system of our country, and probed how to standardize management system of food safety; after that, Compared with the experiences inbound and outbound, the paper discussed the measures of safe food development and management of our country, and regional practices taking Nanjing as a case. In conclusion, the paper put forward the measures to ensure the food safety of our country, and improve the standardize management system, including strengthening resource environmental protection and efficient use through the food safety regulations and standard level, as well as the development of high quality agrifood and effective practice of its management [3].
Consumer as a provider of market demand mostly demands to normalize a unit, food price that equals to the desired utility. All of the farms as the upstream supply chain to provide the only vendor on the downstream supply chain the raw materials that total normalized to a unit. Enterprise supply chain punishment mechanism is exogenous corporate liability: when the food occurs problem, if the products can be traced back to the responsibility of the supply chain enterprises, so sellers need to pay an amount of money to consumers [4]. If the seller has been paid to the consumer, but the responsibility of the food dating back to the farm afterwards, then the farm need to pay a amount of compensation to the seller. Here the number of compensation is exogenous; it can be seen as the mandatory liability that external regulators imposed to the companies.

The probability of the food problem that occurs while the foods goes through the farm and sellers and eventually reach to the consumers:

$$
\lambda\left(e_{i}, e_{j}\right)=g_{m}\left(e_{i}\right)+\sum_{j} \mu g_{f}\left(e_{j}\right)-g_{m}\left(e_{i}\right)^{*} \sum_{j} \mu g_{f}\left(e_{j}\right)
$$

Is the share of each farm's sale on the raw materials due to the homogeneity, each share of the total farm provides the same amount of raw material share? is the probability of the food problems occurs on the sales progress, for example, pollution caused in secondary processing, packaging and preservation process [5], the probability depends on the seller's responsible attitude in production and business activities directly, namely the effort is the probability of food problem when the farm's effort is. We promise, and. Because the higher level of effort farms and sellers played, the lower possibility of the raw materials and semi-finished and finished products appear pollution, cutting corners. Or we can understood as if the enterprise supply chain are willing to pay more for food security elements, then the quality of raw materials, processing technology will be more fits consumers' benefits, resulting to improve product quality, reduce food safety incidents that may occur. Since all of the farms homogeneous, took the case of symmetric equilibrium into consideration directly [6,7], all the farms have chosen the same level of effort, the average of the market accident probability is equal to the probability of a single farm accident:

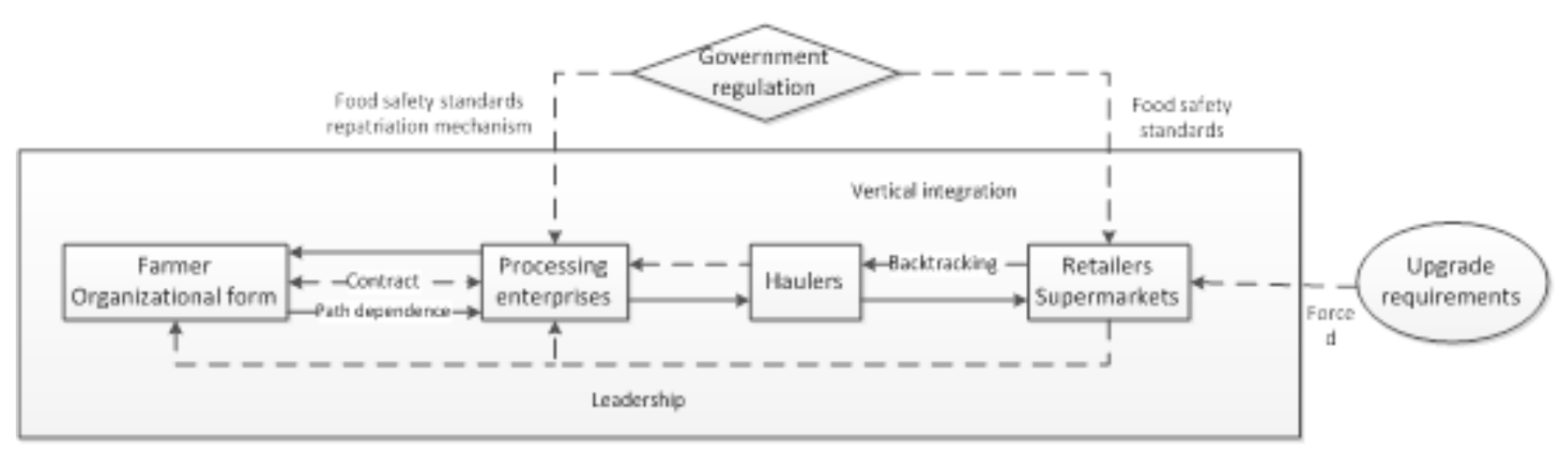

Fig. (1). Supply chain of safety food. 
$\lambda\left(e_{i}, e_{j}\right)=g_{m}\left(e_{i}\right)+\sum_{j} \mu g_{f}\left(e_{j}\right)-g_{m}\left(e_{i}\right) * \sum_{j} \mu g_{f}\left(e_{j}\right)$

The price that consumer pays to the seller:

$P_{m}=\left[1-\lambda\left(e_{i}, e_{j}\right)\right] W+\lambda\left(e_{i}, e_{j}\right)\left(-A+T_{m} L_{m}\right)$

$\mathrm{W}$ is the price that consumers are willing to pay for complete a unit of food security, A is the loss caused to consumers when the food injuries occur, and so on.

Of course, there are other models that can be used to analysis the problem of food safety.

\section{MECHANISM OF CHINESE FOOD SAFETY INCIDENTS}

\subsection{Univar Ate Analysis to Identify the Mechanism of Food Safety Incidents}

The food supply chain includes production link, circulation, processing link, consumer link and recy-cling link, any risks in which will have a negative impact on the entire food supply chain, and hazard food qual-ity and safety. First of all, we analyze the factors that have any impact on food safety, for example, the supply chain links, food categories, enterprise scales and the poss ible causes of food safety incidents, which contribute to a more clear understanding of the mechanism of food safety incidents [8].

\subsection{Food Consumption Link to Food Safety}

In food consumption link, the highest incidence event was retail (123 times, 11.26\%) and catering industries (93 times, $8.52 \%$ ) links. The occurring cause is mostly cheating, total 38 times. Integrated several factors, the retailing problems of large and medium-sized enterprises are mostly happened in large supermarket, involving a variety of reasons, and the common are inconsistent with the actual label, the ex-pried products not off the shelf and so on. The main responsibility for the cheating is individual businesses. There are many reasons. In addition, large and mediumsized enterprises occur food safety incidents frequent, mainly for unsanitary conditions, such as.

\subsection{Supply Chain Links to Food Safety Incidents Occurring}

According to the characteristics of food supply chain, we can classify the food supply chain into five primary links; each level is divided into several second links in Table 1). Because the food safety incidents which result from supervision, inspection and quarantine always occur in the circulation links, we classify the $2^{\text {nd }}$ link of food supervision into $1^{\text {st }}$ link of circulation link. The classification of food safety incidents according to food supply chain links is shown in Table 1. Numbers and frequency that are counted by 2 nod links of the food supply chain is shown in (Fig. 2).

\subsection{Performance Analysis of Food Safety Market Access}

Implementation of the food safety market access impact on social welfare benefits mainly showed in the aspect of the welfare changes in the producer and consumer. As the the main beneficiaries of the consumer-agricultural market access implementation, consumer has become the one to pay compensation to the policy, the producer as a policy adversely affected mainly bear who became the one to accept compensation. Both of them can measure through compensation (CS) because of the changes of the implementation of welfare policy, if the one who pay the compensation, its CS greater than the one accept compensation side, then this policy can improve the level of social welfare, otherwise it will lead to social welfare levels decline.

And the implementation of agricultural market access is tightly constrained by the the amount of agricultural production, blind expansion behaviour that only care about

Table 1. Occurrence of food safety incidents dividing by food supply chain links.

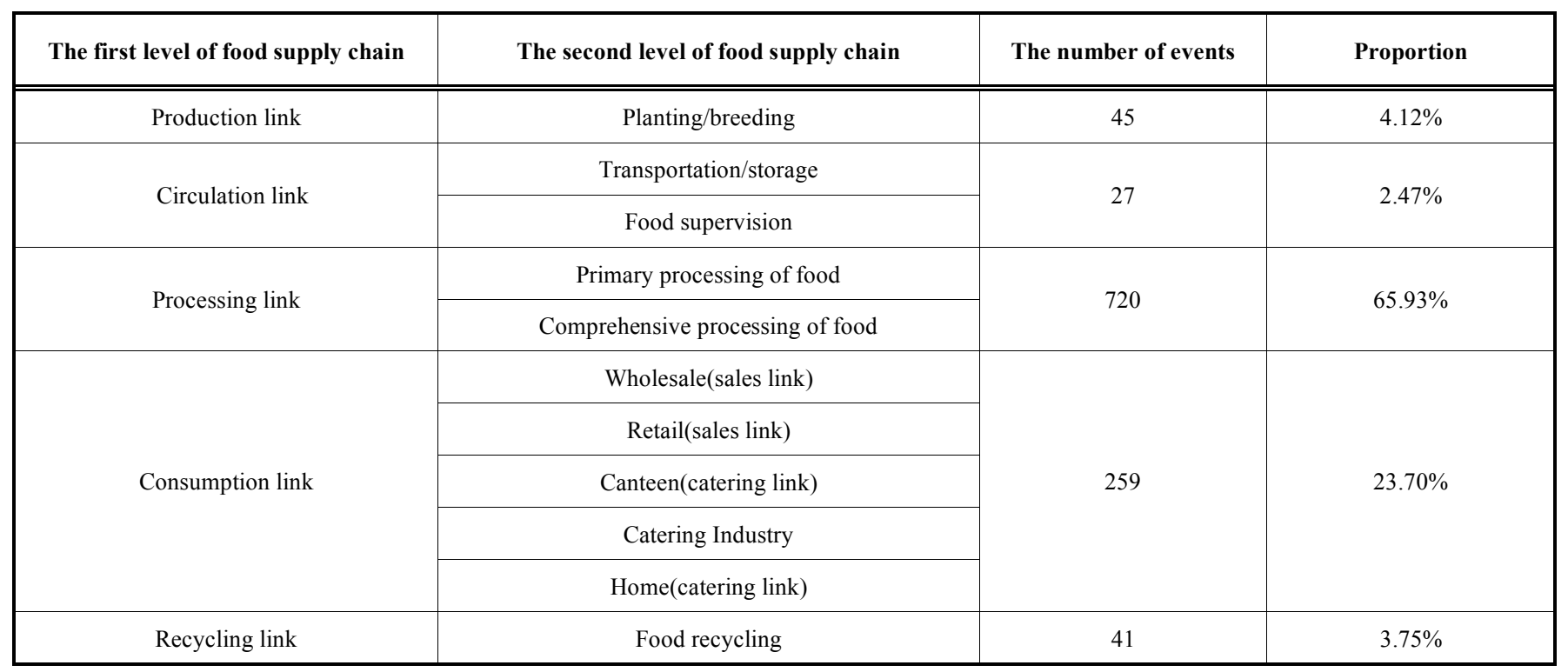




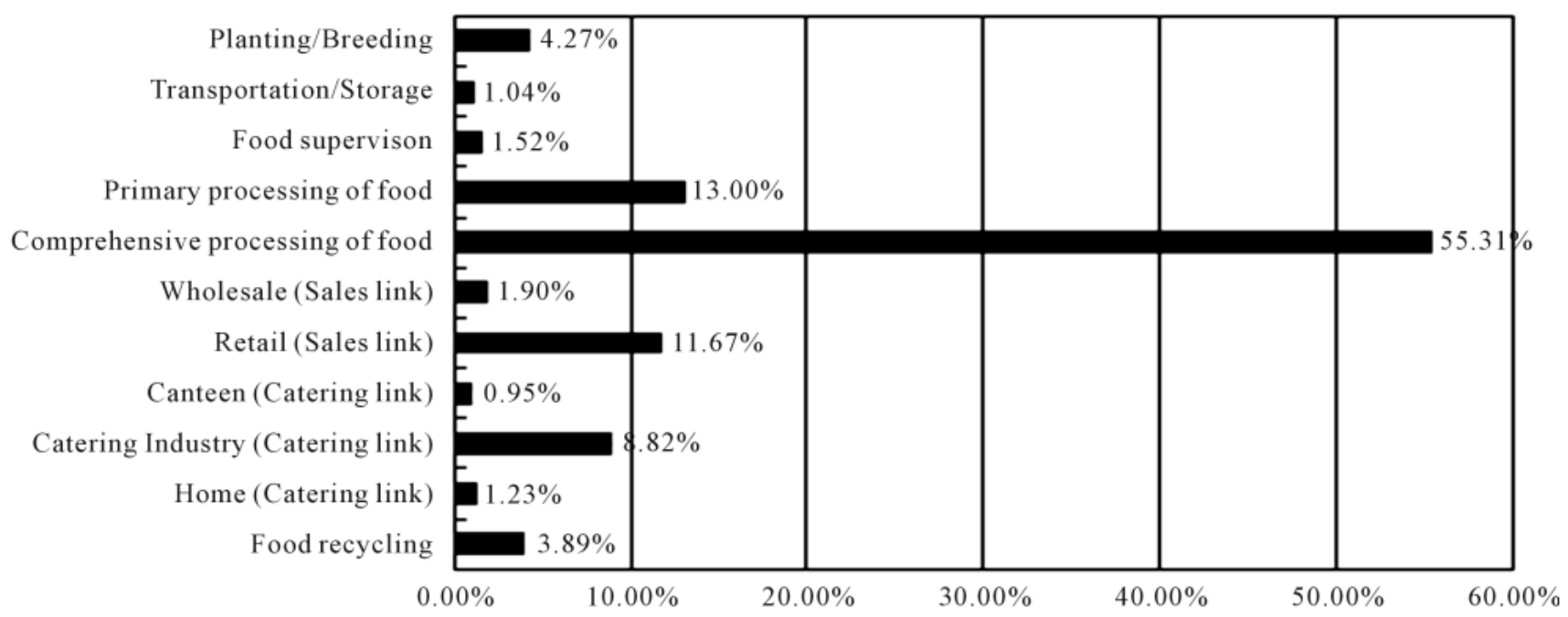

Fig. (2). Occurring proportion of food safety incidents in $2^{\text {nd }}$ food supply chain links.

the quantity but not safety and quality, to improve the quantity and quality of food quality and safety-related public goods, such as the protection and rational use of resources and the environment, strictly control of the food quality and safety standards in the market, etc. then WTP can be regarded as approximately equal to WAT(Robert Doweling, 1976). In case of the one who accept indemnifying got corresponding economic incentives, the implementation of agricultural market access will improve social welfare. Here we will analysis the market access change impact on social welfare in the perspective of the change of consumer welfare as shown in (Fig. 3).

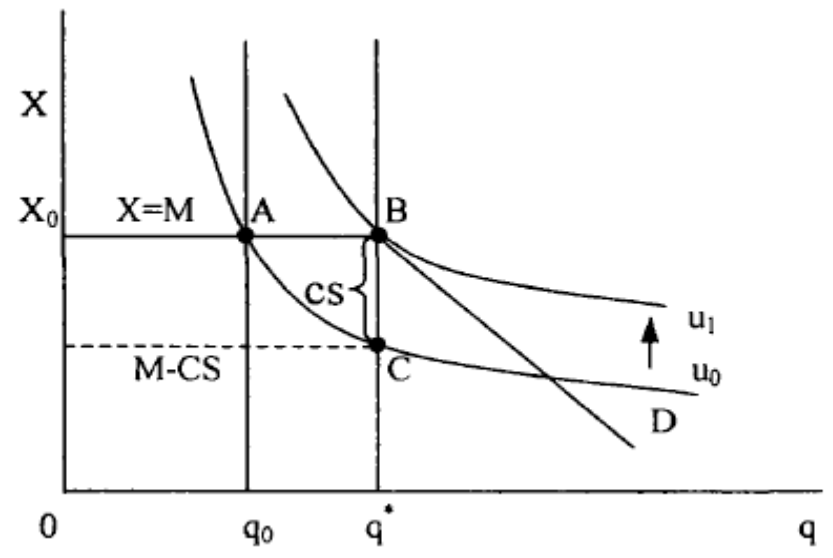

Fig (3). The metering of remaining compensation (CS) under market access conditions.

$\mathrm{X}$ is the number of combinations of food products consumption, $\mathrm{x}$ is corresponding expenditure, $\mathrm{q}$ is the environment and resource services related to the quality and safety of food, $M$ is the currency income that correspond to the consume of food.

According to the graphical analysis, consumers benefit from improvement of food quality and safety which brought by the market access, and did not pay any fees. Producers increasing the cost of agricultural producers in the process of providing equitable market access products, and bear most of the losses [9, 10].

While maintaining the original level of utility, the consumer is willing to pay for high-quality, safe food (such as CS). At the same time, according tithe principles that WAT approximately equal to WTP, producers are also willing to take the initiative to protect and improve food quality and safety at the conditions of receiving appropriate compensation or incentive.

\section{CONCLUSION}

Food safety issues have been widespread concern for the safety of the food supply, but there are many issues worthy of study. The research may have to grasp the problem: First, adopt the method of system and network organization analysis, namely how to relate the behavior of economic agents to the frame of secure food supply. Secondly, using the comparative method of tissue study. All in all, food safety is closely related to the economic system or mechanism. We need to grasp the economic system appropriately, and take a good use of it to guarantee the safety of food.

\section{CONFLICT OF INTEREST}

The authors confirm that this article content has no conflicts of interest.

\section{ACKNOWLEDGEMENTS}

This work is supported by Humanities and Social Sciences of Ministry of Education of the People's Republic of China, "Finance Support Model of Strategic New Industry Based on Venture Investment" (13YJCZH055).

\section{REFERENCES}

[1] J.M. Antle, "Food Safety, Production Structure and the Industrial Organization of the Food Industry", Invited paper prepared for the 
62nd EAAE Seminar and 3rd INRA-IDEI Conference on Industrial Organization and the Food Processing Industry, Toulouse, 12-13 November, 1998.

[2] D.A.J. Hennessy, "Leadership and provision of safe food", American Journal of Agricultural Economics, vol. 4, pp. 862-874, 2001.

[3] N.H. Hooker, R.M. Nagy and J.W. Siebert, "assessing the economics of food safety activities: studies of beef slaughter and meat processing", Working Paper, Texas A\&M University, 1999.

[4] Y.S. Liu, Q.N. Zhang and Q.Q. Li, "A Research on mechanisms and countermeasures of the food safety incidents occurring on food supply chain", Journal of Service Science and Management, vol. 7, 337-345, 2014.

[5] L. Luo, Y. An and C. Gu, "Analysis of sources of risk and regulatory strategy of Chinese food safety", Journal of Food Science and Technology, vol. 31, pp. 77-82, 2013.
[6] R. Miao, "A research on food safety regulatory issues and countermeasures in circulation of China", China Business \& Trade, vol. 9, pp. 17-18, 2013.

[7] A.E. Roth, "The Shapley Value: Essays in Honour of Lloyd S Shapley “, New York: Cambridge University Press, 1988.

[8] A.C. Role, P.L. Pintail, "Pesticides, rice productivity, and farmers' health: an economic assessment", International Rice Research Institute and World Resource Institute, Philippines and Washington D.C., 1993

[9] J.Zhang, Z. Li and J. Zoo, "The key points analysis of supply chain perspective of food quality and safety control", Logistics Engineering and Management, vol. 10, pp. 101-103, 2013.

[10] H. Zhang, Y. An and W. Zhang, "Study on weaknesses, root causes and key issues of China's food quality safety: based on the empirical analysis of 1460 food quality safety cases", Issues in Agricultural economy, vol. 6, pp. 135-141, 2013.

(C) Rong and Lulu; Licensee Bentham Open.

This is an open access article licensed under the terms of the (https://creativecommons.org/licenses/by/4.0/legalcode), which permits unrestricted, noncommercial use, distribution and reproduction in any medium, provided the work is properly cited. 